\title{
Ediciones Serendero: un proyecto personal al servicio de músicos y auditores
}

\author{
por \\ Carmen Peña Fuenzalida \\ Instituto de Música, Pontificia Universidad Católica de Chile, Chile \\ cpenf@uc.cl
}

En un mundo interconectado como el que vivimos, contar con uno o más sitios web es prácticamente imprescindible para los artistas. Para los compositores nacionales de música de la tradición escrita es uno de los principales medios para marcar presencia, en un contexto musical país que se resiste a poner en valor públicamente, en concierto, su trabajo creativo y, en muchos casos, interpretativo.

Ciertamente, los creadores jóvenes, aquellos que nacieron con un computador a su alcance, han sabido aprovechar este recurso. No obstante, son numerosos aquellos de épocas anteriores que permanecen en el anonimato en las plataformas virtuales, a no ser que, por ejemplo, músicos actuales ejecuten su repertorio en un concierto, festival, encuentro o clase magistral, entre otros, y este se transmita o quede registrado digitalmente en algún sitio web de dominio personal o institucional para ser ofrecido al público.

David Serendero Proust (n. 1934), violinista, director de orquesta, compositor, musicólogo y pedagogo, no llegó al mundo con un ordenador en la mano, pero se aventuró con la tecnología e inauguró en 2017 el canal David Serendero en YouTube y en 2020 Ediciones Serendero, editorial digital de música chilena. En ambas plataformas se encuentra disponible variada documentación acerca de su actividad, a libre disposición sus partituras y el registro sonoro de obras de su catálogo, en las que utiliza orquesta y solistas virtuales, tema al que me referiré más adelante.

Serendero es un músico multifacético, de vasta trayectoria. Fue contemporáneo con otros que, a partir de la década del 1950, participaron activamente de una bullente vida musical en el ámbito de la creación, interpretación, difusión, docencia y gestión, como es el caso de Gustavo Becerra, Fernando García, Jorge Peña Hen, León Schidlowsky o Juan Orrego Salas, para mencionar aleatoriamente algunos de ellos. Su interés por la música, en todos los ámbitos, se refleja en su trabajo profesional y también en los comentarios al material que incluye en sus plataformas digitales. Por tal razón, si bien en esta comunicación me referiré en particular a Ediciones Serendero, creo oportuno consignar algunos antecedentes de su labor como músico en Chile y Alemania que iluminan ciertos rasgos de su personalidad artística y, al mismo tiempo, contribuyen a la comprensión de las razones que lo animaron a emprender dicho proyecto.

\section{RESEÑA BIOGRÁFICA}

David Serendero Proust se inició muy joven en la música. A partir de los once años estudió violín en la Escuela Moderna de Música como alumno de Zoltan Fischer, maestro que en esos años era primera viola de la Orquesta Sinfónica de Chile (en adelante OSCH). Al culminar su educación escolar en la Alianza Francesa, ingresó al Conservatorio Nacional de Música como discípulo de Luis Mutschler 
(1896-1972). Posteriormente y mientras continuaba estudiando violín, entre 1953 y 1959 estudió musicología y composición en la Facultad de Ciencias y Artes Musicales de la Universidad de Chile. En esta última carrera, sus maestros de composición fueron Juan Orrego Salas y Gustavo Becerra (Barrientos 2002: 932). Desde su óptica, Orrego Salas es "uno de los mejores compositores y pedagogos chilenos" (Serendero S/Fc), además -comenta-, gracias a él tuvo inicialmente una orientación neoclásica con la que se sintió "muy a gusto". De esta época datan sus primeras obras de cámara y la primera orquestal: Interludio 1959 para orquesta, que ese mismo año obtuvo premio por obra del Instituto de Extensión Musical, y La leyenda de la creación, cantata para soprano, bajo, coro y orquesta (1959), galardonada con el Premio mayor de los Student Composers Awards 1960 de la Broadcast Music, Nueva York, y también con premio por obra del Instituto antes mencionado en $1962^{1}$.

Su motivación por la dirección orquestal se manifestó paralelamente a su trabajo como violinista de la OSCH (1958-1965). Sin embargo, no fue un camino fácil. Por una parte, en Chile no había formación en ese campo y, por otra, desde su óptica, su inquietud no encontró eco en Víctor Tevah, director titular de la OSCH y del Conjunto Instrumental del Conservatorio (Calonge 2004). En ese contexto, buscó de forma privada acceder al conocimiento, interés que se vio favorecido por la creación de la Orquesta Filarmónica, de la que fue miembro fundador (1955-1958), y por las visitas a Chile realizadas por Teodoro Fuchs². Este director alemán-argentino radicado en Buenos Aires, con frecuencia vino a Chile a dirigir y, en esas ocasiones, Serendero tomó clases particulares de dirección orquestal con él (1957-1959). Además, en 1957 participó en un curso de dirección que Fuchs ofreció en el Teatro Municipal, el primero que se realizó en el país. Serendero comenta: "Con él fue con quien más aprendí y quien más influyó en mi formación como director de orquesta” (Serendero S/Fb: 4).

Entre 1960 y 1962 fue becado por la Escuela Superior de Música de Stuttgart con el fin de perfeccionar sus estudios de violín y dirección orquestal. La beca le fue ofrecida por el Gobierno de la República Federal Alemana (Comité Editorial 1960: 139). En 1962 recibió el título estatal de profesor de violín. A su regreso a Chile se reincorporó como violinista a la OSCH, obtuvo una contratación como profesor del Conservatorio Nacional, tuvo a su cargo la dirección del Ballet Nacional de Chile y comenzó a conducir la OSCH como director invitado. La crónica de Revista Musical Chilena es nutrida en información acerca de esta etapa y su buen desempeño como director orquestal. Bajo mi perspectiva, Juan Pablo Izquierdo, Agustín Cullell y David Serendero, se perfilaban como la nueva generación de directores.

Desde mediados de los años sesenta hasta su vuelta a Alemania (1972) su actividad fue intensa, ya que asumió diversas obligaciones que, además, en algunos casos implicaron gestión artística. Por ejemplo, entre 1965 y 1966, se trasladó a Osorno encomendado por la Universidad de Chile para asumir como profesor en el recién inaugurado Centro Universitario Osorno, plantel en donde también fundó y dirigió la Escuela de Música que ofreció diversos cursos de perfeccionamiento. Paralelamente, tuvo a su cargo la dirección de la Orquesta Filarmónica Osorno, con la que ofreció numerosos conciertos en diferentes ciudades del sur de Chile, incluyendo lugares a los que nunca había llegado un conjunto orquestal (Serendero S/Fb: 29-40). Una noticia de la crónica de Revista Musical Chilena elogia esta iniciativa fundacional:

El joven director de orquesta y violinista, David Serendero, en el breve lapso de dos meses, ha creado en Osorno una Orquesta de Cámara, denominada Orquesta Filarmónica de Osorno, de la que es director titular, y ha organizado una temporada de conciertos, que se inició el 3 de junio [1965] en el Teatro Municipal de Osorno. Cada uno de los conciertos de la ciudad de Osorno será repetido en la Casa del Arte de Puerto Montt al día siguiente. Esta encomiable labor de difusión musical y cultural que se inicia a través de esta agrupación orquestal, merece destacarse de manera muy especial. Para la temporada de 1965 se han programado seis conciertos en Osorno y seis en Puerto Montt, los que serán dirigidos por el maestro Serendero (Comité Editorial 1965: 104).

1 Serendero S/Fa: 24, 18-20. Estas obras no figuran en el listado de obras seleccionadas y ejecutadas en los festivales de Música Chilena,1948 - 1979 estudiados por Merino (1980).

2 En enero de 1960 Fuchs asumió la dirección de la OSCH por algunos meses (Comité Editorial 1960: 138). 
Los pasos siguientes en su trayectoria fueron la dirección del Conservatorio Nacional de Música (1968-1970), la creación de la carrera de dirección orquestal, la única en Latinoamérica en esa época, y la reorganización de la Orquesta del Conservatorio. Simultáneamente, fue director de la OSCH (19671972) y, por su gran aporte, fue galardonado con el premio anual de la crítica, en la especialidad de música, por el Círculo de Críticos de Arte (1969) (Serendero S/Fb: 60). Estos años fueron difíciles y, en una mirada retrospectiva, Serendero los recuerda de la siguiente manera:

En 1968 los estudiantes se tomaron la Universidad de Chile e impusieron diversos cambios inspirados en el modelo norteamericano. Todos los cargos directivos fueron electos, la universidad se "democratizó" y "politizó". Los jefes de servicio perdieron atribuciones y los partidos políticos tuvieron la palabra. En la Facultad de Ciencias y Artes Musicales (hoy Facultad de Artes) el partido comunista alcanzó mayoría en casi todos los consejos universitarios. Las resoluciones comenzaron a tomarse en el partido, quien se oponía a ellas era catalogado de retrógrado. En mis dos cargos directivos frente a la Orquesta Sinfónica y al Conservatorio Nacional los problemas aumentaron gradualmente, hasta que a mediados de 1972 opté por presentar mi renuncia y exiliarme a Alemania (Serendero S/Fb: 73).

Durante su estadía en Alemania (1973-2008) fue miembro de la Filarmónica Renana de Koblenz hasta su jubilación en 1999. Paralelamente, le ofrecieron la dirección artística del Collegium Musicum Renano, con sede en Wiesbaden. Participó en numerosos conciertos, dirigió en distintos escenarios y estrenó obras suyas, como muestra su catálogo. Un aspecto destacable del Collegium Musicum Renano es el espacio que abrió a músicos chilenos destacados para que actuaran como solistas. En su documentación, Serendero consigna no menos de doce intérpretes, incluyendo directores de orquesta (Serendero S/Fb: 104-105).

De regreso en Chile desde 2007, ha engrosado su catálogo creativo con varias obras, al mismo tiempo que ha realizado seminarios, conferencias y ofrecido numerosas entrevistas, especialmente, para dar a conocer sus ediciones y su trabajo con la orquesta y solistas virtuales, producciones que le han permitido implementar sus sitios web.

\section{EDICIONES SERENDERO: UN PROYECTO CUYA META FINAL ES TO PUT CHILEAN MUSIC ON THE MAP (Serendero S/Fb: 134)}

El paso del soporte digital físico, como el CD por ejemplo, a la digitalización, distribución y consumo mediante plataformas digitales, ha significado un gran cambio en los hábitos y prácticas musicales tanto de los oyentes como de los creadores de la música de la tradición escrita. Si bien no entraré en detalles acerca de las fortalezas y debilidades de estas plataformas, desde mi óptica, entre los grandes beneficios que ofrece la tecnología para los oyentes es el infinito universo de música disponible en diferentes formatos y en el momento que se requiera. Para los profesionales de la música es una posibilidad real de personalizar un sitio de acuerdo con las necesidades y objetivos específicos y administrar su producción de modo personal y autónomo, sin depender de la gestión mediada por una institución musical, una productora o una editora que se interese en su trabajo. Además, la interconexión con el resto de mundo es rápida, es un medio más interactivo que otros y su costo de creación y mantención no es demasiado elevado. Sin embargo, especialmente en el caso de los creadores e intérpretes, la otra cara de la moneda es que la circulación de la música puede verse afectada si la distribución corre por cuenta del propio músico y su gestión no es la adecuada o lo suficientemente eficaz.

Considerando los beneficios de este medio, como ya se adelantó, David Serendero se aventuró a utilizar plataformas digitales poniendo a libre disposición su producción musical. Pero ¿por qué incursionar en el campo de la edición?, ¿en qué lo beneficia la creación de una empresa sin fines de lucro, gratis para escuchar y descargar música?

Varias razones pesaron para emprender esta cruzada. Entre ellas, en 2009 tuvo la intención de trabajar en un proyecto de difusión de la música nacional, pero no encontró eco en instituciones musicales y culturales para su concreción. Por tal motivo -dice- "Desistí entonces de buscar ayuda externa y me dediqué a preparar la creación de una editorial sin fines de lucro por cuenta propia” (Serendero 
S/Fb: 134). Así nació en 2020 el sitio web Ediciones Serendero³. Pero el camino fue más largo. Aún encontrándose en Alemania, se interesó por editar su música con programas computacionales, llegando finalmente a la elección del editor Sibelius, mientras la interpretación podía realizarla con el Collegium Musicum Renano, estrenando obras cada cierto tiempo. Por otra parte, también pensó en publicar discos ya que no contaba con grabaciones suyas, pese a que las había dirigido con diferentes orquestas. Sin embargo, consideró que los registros de concierto en vivo no estaban en óptimas condiciones. Fue entonces cuando, luego de conocer las cualidades de Garritan Personal Orchestra, optó por la orquesta virtual (Menanteau 2017), como explica en una entrevista: "una biblioteca de sonidos digitales grabados en vivo con los mejores instrumentos a nivel mundial. Esa es la ventaja de este programa. El sonido no es producido por el computador sino por un instrumentista grabado en vivo y con micrófono" (Menanteau 2018). Garritan ofrece distintas posibilidades de instrumentos para escoger según las necesidades y los detalles se ajustan manualmente.

De este modo, entre 2017 y 2019 publicó la serie David Serendero y su orquesta virtualy David Serendero y sus solistas virtuales, cuatro y dos discos compactos respectivamente, en versiones realizadas con el software de notación musical Sibelius y la colección de sonidos Garritan Personal Orchestra. Luego se sumó David Serendero el director, otros seis discos, esta vez con registros de conciertos de distintas orquestas dirigidas por él. A propósito de las dos primeras series, Fernando García (2017) llamó la atención señalando:

En dichos fonogramas se incluyen ocho atractivas obras orquestales del compositor, algunas de estas están sin estrenar en Chile, abriendo así la vasta posibilidad para que muchas creaciones de nuestros compositores lleguen al público, y no solo en nuestro país, por medio de los recientes procedimientos técnicos empleados por David Serendero en la elaboración de su serie ya en circulación (García 2017: 281).

Es importante mencionar que, además de estar disponibles en su canal de YouTube, hay versiones MP3 de todas las series mencionadas y de otras, según señala Serendero (Serendero S/Fa: 24),

[... en al menos 28 sitios web. Este número va aumentando año a año, a medida que aparecen nuevas plataformas digitales. Entre ellas están Akazoo, Amazon, Bandcamp, Claro Musica, Deezer, Google Play, iTunes, Napster, PortalDisc, Shazam, Soundcloud, Spotify, Tidal, TikTok, Yandex y YouTube Music.

Pero volviendo a Ediciones Serendero, el sitio -como muchos otros- está organizado a partir de un menú principal: "Inicio”, tres categorías para la búsqueda de repertorio -música sinfónica, música de cámara y obras didácticas-, una sección denominada "Acerca de Serendero", para finalizar con las opciones "Iniciar sesión" y "Contacto". Se puede acceder a la versión en español o en inglés.

El "Inicio" es una bienvenida con una muestra de fotos personales y de conjuntos musicales (slideshow), más información relativa al contenido y propósitos del sitio ${ }^{4}$ :

Ediciones Serendero es una empresa sin fines de lucro, que ofrece gratuitamente la mayor parte de la música de David Serendero. Cada obra tiene una página propia, donde Ud. podrá escuchar el audio mientras hojea la partitura, ver el video correspondiente o bien descargar partitura y partes para ser impresas por Ud. mismo.

Para descargar música, se solicita registrarse, comprometiéndose a guardar reserva de los datos de terceros y a no utilizarlos para publicidad de ningún tipo. También, Serendero de antemano agradece que le informen de la ejecución pública de las obras contenidas en el catálogo y, finalmente, notifica que es posible obtener certificado de copia autorizado, debido a la prohibición de muchos países de utilizar fotocopias de la música en conciertos públicos.

Cada categoría musical está provista de un listado de obras con su respectivo año de creación y la duración. La opción música sinfónica reúne doce creaciones instrumentales y una sinfónico-coral,

3 Sitio web www.edicionesserendero.cl [acceso: 12 de mayo de 2020].

4 https://www.edicionesserendero.cl/inicio/ [acceso: 12 de mayo de 2020]. 
la cantata para soprano, bajo, coro y orquesta La leyenda de la creación (1959). En música de cámara presenta un total de nueve obras: tres para piano, dos para violín y piano, dos tríos de cuerdas y dos para saxofón. Finalmente, las obras didácticas consignadas son dos: El violín de Leonardo (1985), método para niños en edad preescolar y escolar temprana, dedicado a su hijo, cuya versión disponible está en francés. Por su parte, Seis canciones para piano (1956) corresponde a su primera obra compuesta como estudiante de composición que le pareció "digna" de incluir en su catálogo. También se replica en la sección música de cámara. Salvo una obra del extenso listado, Homenaje para cuarteto de saxofones (2006-2007) dedicada a Miguel Villafruela, todas las versiones son con orquesta y solistas virtuales.

Estas categorías abarcan producción entre 1956 y 2014, por tanto se encuentran representadas distintas épocas de su creación en Chile y Alemania, incluyendo algunas de sus tiempos de estudiante, e incluso con anterioridad a sus estudios de composición en la Universidad de Chile. Ese es el caso del Trío 1952 para 2 violines y viola, el que fue revisado posteriormente, según comenta, otorgándole "una nueva redacción, transformándose en un trío de cuatro movimientos y tomando su forma definitiva en 1970". Está dedicado a su maestro Zoltan Fischer, quien falleció ese mismo año ${ }^{5}$.

A cada composición se accede simplemente por medio de un clic en el título deseado. Escuetamente informa la dedicatoria (si corresponde), la duración y la instrumentación en las obras sinfónicas. Asimismo, ofrece la posibilidad de escuchar el audio revisando simultáneamente la partitura, además de opciones para descargar esta última y las partes instrumentales. La portada de todas las ediciones es sobria, la grafía clara, apta para imprimir, y con una introducción escrita en español, inglés y alemán.

Los videos acerca de las obras también contienen rica información. Cada uno está introducido por el propio Serendero que provee de datos generales, en algunos casos bastante personales, en torno a la motivación que tuvo para componerla, lugar y fecha de estreno, dedicatoria y una breve referencia a la estructura musical. Sin evadir terminología especializada, el lenguaje es sencillo y directo. A medida que transcurre la música del video, una diapositiva didáctica, de gráfica sobria, anuncia los movimientos (en caso de haberlos) e incluso llama la atención hacia temas o motivos principales, conforme van apareciendo en la audición. En ocasiones se intercalan sugerentes fotografías. Es pertinente reiterar que siempre es específico en indicar cuándo se trata de la versión de David Serendero y su orquesta virtual o su propia dirección orquestal. Este dato no es menor, ya que en algunas obras hay intérpretes colaboradores con la orquesta virtual, como es el caso de Estampas de la Patria para contralto, tenor, narrador y orquesta (2003-2005), en la que participan la contralto Ana Navarro, el tenor Felipe Gutiérrez y David Serendero como narrador, más la orquesta virtual ${ }^{6}$.

La sección "Acerca de Serendero" permite acceder a detallada y nutrida información curricular, documentación de su trayectoria, un exhaustivo catálogo de producción creativa, de discos compactos y de escritos, a los que se suma una selección de cuatro videos que contienen entrevistas que le realizaron con distintos motivos. Estas, así como otras, también se encuentran disponibles en su canal de YouTube.

\section{COMENTARIO FINAL}

El sitio Ediciones Serendero es amigable, está dirigido a un público amplio, no requiere de conocimientos técnicos por parte del usuario y, especialmente, la calidad del sonido de audios y videos es buena. Desde mi perspectiva, cumple la función para la que fue creado. Es decir, difundir la creación de Serendero y motivar a los músicos intérpretes a ejecutarla en concierto. En este sentido, Serendero es claro y lo reitera en diferentes entrevistas. No obstante, desde otro punto de vista, visitar el sitio es como recorrer un álbum autobiográfico. Se puede revisar con diferentes miradas y comenzar en cualquier parte, pero mantiene un sello personal congruente con lo que su autor dice y muestra en sus videos, con lo que escribe en los documentos que proporciona y también con música. En este sentido, es también una fuente para estudios futuros, tanto acerca de diversos aspectos de la trayectoria y estética musical de David Serendero, como también de episodios de la historia musical chilena vistos bajo el prisma del autor, un músico que ha hecho de una plataforma digital un objeto de memoria.

5 https://www.edicionesserendero.cl/trio-1952/ [acceso: 12 de mayo de 2020].

6 https://www.edicionesserendero.cl/estampas-de-la-patria/ [acceso: 12 de mayo de 2020]. 


\section{BIBLIOGRAFÍA}

BARRIENTOS, LINA

2002 "Serendero Proust, David". Diccionario de la Música Española e Hispanoamericana. Emilio Casares (editor), Madrid: Sociedad General de Autores y Editores, vol. 9, pp. 931-932.

Calonge, Manuel

2004 Entrevista a David Serendero. Santiago: Radio Universidad de Chile, 1 de septiembre (transmitida en enero de 2005). Disponible en: https://www.youtube.com/watch?v= HCafTuZMn70\&feature=emb_logo [acceso: 20 de julio de 2020].

\section{Comité Editorial}

1960 "Noticias”, Revista Musical Chilena XIV/69, pp. 138-140. Consultado de https:/ / revistamusicalchilena.uchile.cl/index.php/RMCH/article/view/13033/13315 [acceso: 20 de julio de $2020]$.

1965 "Noticias", Revista Musical Chilena XIX/92, pp. 101-105. Consultado de https://revistamusicalchilena.uchile.cl/index.php/RMCH/article/view/28476/30199, p. 10 [acceso: 20 de julio de 2020].

García, Fernando

2017 "David Serendero presenta discos digitales". Revista Musical Chilena LXXI/227 (enero-junio), p. 281, Disponible en: https://revistamusicalchilena.uchile.cl/index.php/RMCH/article/ view/46880/51569 [acceso: 12 de septiembre de 2020].

Menanteau, Álvaro

2017 "Entrevista a David Serendero". Santiago: Radio USACH (Universidad de Santiago), 5 de octubre. Disponible en: https://www.youtube.com/watch?v=KAc2cNrLXLU\&feature=emb_logo [acceso: 23 de julio de 2020].

2018 "Entrevista a David Serendero". Santiago: Radio USACH (Universidad de Santiago), 28 de mayo. Disponible en: https://www.youtube.com/watch?v=zJLLDtwxhew\&list=PL0ZF7Bnit goUg4R6ZcIpkm0dMNsix2srx\&cindex=12 [acceso: 23 de julio de 2020].

Merino Montero, Luis

1980 "Los Festivales de Música Chilena: génesis, propósitos y trascendencia”. Revista Musical Chilena XXXIV/149-1, pp. 80-105. Consultado de https://revistamusicalchilena.uchile.cl/ index.php/RMCH/article/view/1565/1448 [acceso: 12 de septiembre de 2020].

SEREndero, DAVID

S/Fa "Catálogo de la obra de David Serendero". Disponible en: https:/ /www.edicionesserendero. cl/wp-content/uploads/2020/11/Catalogo-1.pdf [acceso: 3 de diciembre de 2020].

$\mathrm{S} / \mathrm{Fb} \quad$ "Documentación de David Serendero". Disponible en: https://www.edicionesserendero. cl/wp-content/uploads/2020/11/Documentacion.pdf [acceso: 3 de diciembre de 2020].

S/Fc "Serendero: el compositor". Disponible en: https://www.youtube.com/watch?v=XcGstMg qhO8\&list=UUcHxqFjrRV455W4Z57PcvjQ\&index=23 [acceso: 12 mayo de 2020]. 